
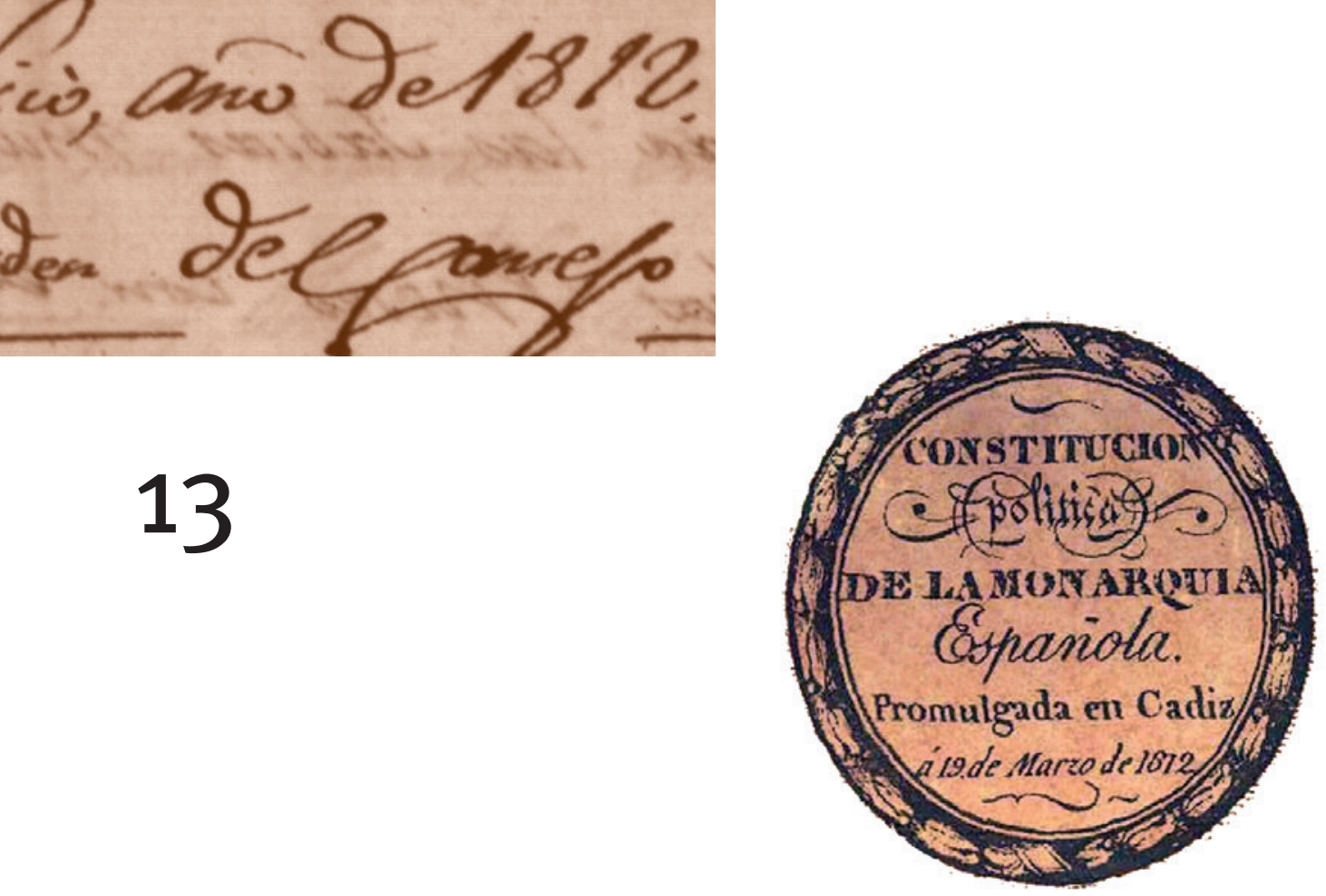

13

romulgada en Cadiz
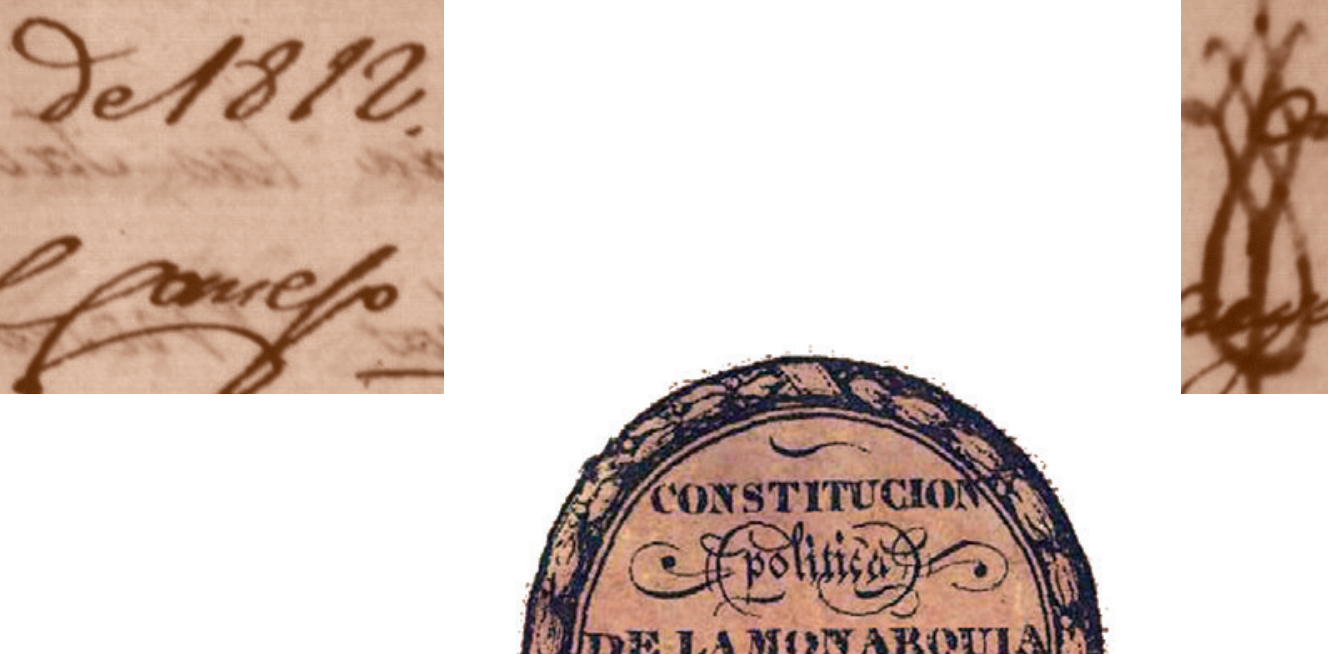



\section{Colección $\mathbf{I m u d}$ \\ n. ${ }^{\text {13 }}$}

\section{LA PROVINCIA DE LA MANCHA Y LA CONSTITUCIÓN DE 1812}





\section{Carlos Chaparro Contreras \\ e Isidro Sánchez Sánchez (eds.)}

\section{LA PROVINCIA DE LA MANCHA Y LA \\ CONSTITUCIÓN DE 1812}

Ediciones de la Universidad

de Castilla-La Mancha

Cuenca, 2021 
LA PROVINCIA de La Mancha y la Constitución de 1812 / editores, Carlos Chaparro Contreras, Isidro Sánchez Sánchez.- Cuenca : Ediciones de la Universidad de Castilla-La Mancha, 2020

341 p. ; 24 cm.- (Almud ; 13)

ISBN 978-84-9044-311-8

1. España - Constitución - 1812 2. Castilla-La Mancha - Historia I. Chaparro Contreras, Carlos, ed. lit. II. Sánchez Sánchez Isidro, ed. lit. III. Universidad de Castilla-La Mancha, ed. IV. Serie

342.4(460)"1812"

946.028

1DSE-ES-G

NHD

(C) de los textos e imágenes: sus autores.

(C) de la edición: Universidad de Castilla-La Mancha.

Edita: Ediciones de la Universidad de Castilla-La Mancha y Centro de Estudios de Castilla-La Mancha.

Colección Almud n. ${ }^{\circ} 13$.

Diseño de la colección:

C.I.D.I. (Universidad de Castilla-La Mancha).

unte Unión de Edtorlales
Universitarias Españolas nacional.

Esta editorial es miembro de la UNE, lo que garantiza la difusión y comercialización de sus publicaciones a nivel nacional e inter-

ISSN: $1988-0979$

I.S.B.N.: 978-84-9044-311-8 (Edición impresa)

I.S.B.N.: 978-84-9044-434-4 (Edición electrónica)

D.O.I.: http://doi.org/10.18239/alm_2021.13.00

D.L.: CU 248-2019

Composición: Compobell S.L.

Impresión: Gráficas Izquierdo

Hecho en España (U.E.) - Made in Spain (U.E.)

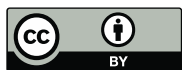

Esta obra se encuentra bajo una licencia internacional Creative Commons CC BY 4.0.

Cualquier forma de reproducción, distribución, comunicación pública o transformación de esta obra no incluida en la licencia Cretative Commons CC BY 4.0 solo puede ser realizada con la autorización expresa de los titulares, salvo excepción prevista por la ley. Puede Ud. acceder al texto completo de la licencia en este enlace: https://creativecommons.org/licenses/by/4.0/deed.es 


\section{ÍNDICE}

Presentación ..................................................................................

Gabino Marco Solera, Carmen María Montalbán Martínez y Antonio Ruiz Lucas

Las Cortes y la Constitución de Cádiz: contenidos sociales y esperanzas populares

Juan Sisinio Pérez Garzón

La Constitución de 1812

Enrique Belda Pérez-Pedrero

Guerra y revolución en La Mancha Ángel Ramón del Valle Calzado

El Partido de Alcaraz a finales del Antiguo Régimen

65 Carmen Hernández López y Francisco García González

"Napoleón emperador" y el destino del Partido de Almagro......... José Gregorio Cayuela Fernández

La Mancha, 1812: El partido judicial de Villanueva de los Infantes Lucía Crespo Jiménez

Representación y educación político-popular en las ceremonias y fiestas de proclamación y jura de la Constitución de 1812 en La Mancha

Carlos Chaparro Contreras

La crisis del Antiguo Régimen en La Mancha (1787-1808). El caso de Villanueva de los Infantes y su partido.... Carlos Javier Rubio Martínez 
Los manchegos que auparon a la "Pepa"

Enrique Jiménez Villalta

Almadén y la Constitución de Cádiz (1812-1814)

245

Julián Prior Cabanillas

El padre Agustín de Castro y la prensa periódica

273 Isidro Sánchez Sánchez 


\title{
LOS MANCHEGOS QUE AUPARON A LA “PEPA”
}

\author{
ENRIQUE JIMÉNEZ VILLALTA \\ Sociólogo Y TÉCNICO de GeTión Cultural
}

La Mancha, por su ubicación en el centro de la Península Ibérica, jugó un papel estratégico destacado en el transcurso de la Guerra de la Independencia y no fue menos importante la labor desarrollada por los diputados de la provincia de La Mancha en la elaboración de la Constitución de 1812 y en la obra general de las Cortes de Cádiz hasta mayo de 1814.

Con la invasión francesa, la Junta Central Suprema, transformada en Consejo de Regencia por la ausencia del Rey, asumió la dirección de la guerra y la reconstrucción del Estado. Para llevar a cabo el proceso reformista se convocaron Cortes Generales y Extraordinarias.

El 22 de mayo de 1809 se aprobó el Decreto sobre restablecimiento y convocatoria de Cortes expedido por la Junta Suprema gubernativa del Reino ("Consulta al país»), que entre otros puntos establecía: "Que se restablezca la representación legal y conocida de la Monarquía en sus antiguas Cortes, convocándose las primeras en todo el año próximo, o antes si las circunstancias lo permitieren".

El decreto de 1 de enero de 1810, con la Instrucción que deberá observarse para la elección de diputados de Cortes, comenzaba así: "La elección de diputados de Cortes es de tanta gravedad e importancia, que de ella depende el acierto de las resoluciones y medidas para salvar la Patria, para restituir al Trono a nuestro deseado Monarca y para restablecer y mejorar una Constitución que sea digna de la Nación española”.

Como veremos, la influencia de la religión y de la Iglesia en el proceso electoral fueron más que notables. El sistema establecía un sufragio indirecto en tres niveles, parroquia, partido judicial y provincia, en el que podían participar todos los hombres avecindados en el territorio con casa abierta y con una edad mínima de 25 años, siendo necesario para ser candidato poseer una renta anual mínima procedente de bienes propios. 
Las Cortes Generales y Extraordinarias abrieron sus puertas el 24 de septiembre de 1810 en el Teatro de la Isla de León y en febrero de 1811 se trasladaron al oratorio de San Felipe Neri de Cádiz, hasta el 20 de septiembre de 1813 que terminaron los trabajos. Las discusiones tuvieron lugar en pleno asedio francés; de la ciudad superpoblada por refugiados de toda España y con una epidemia de fiebre amarilla. Los debates de las Cortes de Cádiz desvelaron la existencia de tres tendencias políticas según el calado de las reformas pretendidas: absolutistas o "serviles", moderados o "jovellanistas" y los liberales, deseosos de un cambio profundo del sistema ${ }^{1}$.

A la primera sesión asistieron, según el Diario de sesiones, 102 diputados. Firmaron la Constitución 185 y en la sesión de clausura, el 14 de septiembre de 1813, participaron 223.

\section{Elección de diputados POR la provinCia de La Mancha Para Cor- TES GENERALES Y EXTRAORDINARIAS (1810-1813)}

Atendiendo a la Instrucción de 1 de enero de 1810, se tenían que elegir 240 diputados. A la provincia de La Mancha, con 205.548 habitantes según el censo del año 1797, le correspondían cuatro diputados (uno por cada 50.000 almas), más uno suplente. Conviene precisar que la organización territorial de aquella época, anterior a la diseñada en 1833 por Javier de Burgos, no se corresponde con la actual. A la provincia de La Mancha de 1810 pertenecían muchas localidades que hoy son de Albacete, Toledo o Jaén y otras que pertenecen ahora a Ciudad Real, eran entonces de Córdoba (Chillón y Gualdalmez) o Toledo (Alcoba, Arroba, Horcajo, Navas de Estena o Retuerta).

El proceso electoral estuvo lleno de incidencias e irregularidades por la ocupación de casi toda la provincia por los franceses y por los intentos manipuladores de algunos miembros de la Junta electoral. Según la instrucción, las Juntas, parroquiales, de partido y provinciales, debían celebrase de la siguiente forma:

"En el domingo señalado para celebrarla, se cantará una Misa solemne del Espíritu Santo, á la cual asistirá el Ayuntamiento, y después del Evangelio hará el Cura párroco una exhortación enérgica al pueblo, en la cual, después de recordarle los horrores de la guerra que tan injustamente nos hace el tirano de la Francia, el infeliz cautiverio de nuestro amado Rey Fernando VII y la estrecha obligación en que todo español se halla de contribuir á la defensa de la Religión y de

1 E. González Calleja y J. Moreno Luzón, Elecciones y parlamentarios, dos siglos de historia en Castilla-La Mancha, Toledo, JCCM, 1993. 
la Patria, le recomendará con la mayor eficacia la madurez y discernimiento con que deberá proceder en las elecciones, porque de ellas depende en gran manera el logro de tan preciosos bienes.

Concluida la Misa, la Justicia, Ayuntamiento, Cura y pueblo se dirigirán al lugar destinado, para celebrar la Junta, la cual será presidia por el Ayuntamiento ocupando el Cura la derecha del Alcalde.

Colocados en orden todos los parroquianos, se llegarán uno por uno á la mesa en que estarán las personas, que presidan la Junta, y dirán el sujeto que nombran para elector de la parroquia, el cual deberá ser parroquiano de ella, y el Escribano lo escribirá en una lista á presencia de los que presiden la Junta.

Concluído el acto, examinarán éstos la lista y publicarán en alta voz aquellos 12 sujetos que hayan reunido mayor número de votos, los cuales quedarán elegidos para nombrar el elector que ha de concurrir á la cabeza del partido.

Los 12 electores nombrados se reunirán separadamente antes de disolverse la Junta, y conferenciando entre si, procederán á nombrar el elector de aquella parroquia, cuya eleccion deberá recaer en aquel sujeto que reuna más de la mitad de los votos. En seguida se publicará el nombramiento.

Desde el lugar en que haya celebrado la Junta parroquial, se dirigirá el concurso procesionalmente á la iglesia, en donde se cantará un solemne Te Deum. El elegido irá en la procesión entre el Alcalde y Cura párroco.

La tarde del mismo día, á presencia de la Justicia, Ayuntamiento, Cura párroco y Diputado elector, habrá baile público en sitio descubierto, carreras de á pie y á caballo, se tirará al blanco, y se tendrán aquellos ejercicios, acostumbrados, asignando algun premio de honor a los que más se hayan distinguido en los ejercicios”.

La elección tuvo que hacerse en las Reales Fábricas de San Juan de Riópar, por tener el enemigo ocupado casi todo el territorio de la provincia y de forma precipitada por encontrarse los franceses cerca de Alcaraz, a tan solo cinco horas de camino. Así lo relataba la Junta Electoral en una comunicación fechada el mismo día de la elección 16 de agosto de 1810:

"Para llevar a efecto lo resuelto por V.M. con relación a la elección de Diputados a Cortes, en su Real Decreto de 18 de junio próximo, acaba esta provincia de dar las pruebas menos equívocas de su misión y respeto a V.M. y de su incontestable patriotismo pues en consecuencia de la convocación de esta junta de 26 del anterior mes, se ha 
celebrado hoy en este sitio la elección de los cuatro Diputados y un suplente que corresponden a La Mancha sobre todos los embarazos que le ha opuesto la presencia del enemigo, que noticioso de esta operación, ha procurado entorpecer con el continuo movimiento de las dos columnas volantes que incomodan y afligen a los pueblos de los cuales, más de dos han sido sorprendidos en el acto de publicación de las órdenes o en las de las diligencias prevenidas en la Instrucción y aunque su conato se ha extendido hasta estas inmediaciones, lo ha dejado ilusorio el celo y la constancia de estos dignos vasallos de S.M. a quien con el mayor respeto dirige la Junta, testimonio del acta de dichas elecciones con la doble satisfacción de haber convocado en la ocasión que esta provincia conserva ileso su espíritu y opinión pública con respecto a sus verdaderos intereses y común causa”.

En una carta enviada el 12 de septiembre de 1810 al Consejo de Regencia, por Gerónimo Sanz Calvo, cura de Ayna, detalla cómo se desarrolló la elección de los diputados por la provincia de La Mancha y el proceso electoral en el partido de Alcaraz, al tiempo que se quejaba de las manipulaciones y solicitaba la adopción de medidas para restituir la legalidad ${ }^{2}$.

La versión ofrecida por Gerónimo Sanz difiere notablemente con las comunicaciones enviadas por Juan Bautista de Erro y Azpiroz, Intendente de la provincia de La Mancha, organizador del proceso electoral y con las actas oficiales extendidas. Las elecciones en las parroquias del partido de Alcaraz fueron el 9 de agosto de 1810. El día 10, los 23 electores parroquiales se desplazaron a las Reales Fábricas de San Juan de Riópar y al día siguiente verificaron la votación de los cuatro representantes del partido. El día 15 llegaron los vocales de los partidos de Infantes y Alcázar de San Juan y el 16 tuvo lugar la votación.

Según Gerónimo Sanz, mientras el Intendente y otros miembros de la Junta Electoral se alojaron en la pieza más principal y mejor de la casa del director de las Reales Fábricas, los demás tuvieron que mendigar alojamiento y comida. Así nos relataba lo sucedido el mismo día de la votación:

"Repentinamente en la mañana del día 16 fueron llamados sin más formalidad, que la de un simple recado los Doce Diputados de Alcaraz, Infantes y Alcázar de San Juan echando también de menos a los de Ciudad Real que suponían que no habrían podido venir por alguna causa legítima. Y conducidos a una antesala de la casa que habitaba el intendente en que presidieron dos solos individuos de la Junta, el

2 Archivo del Congreso de los Diputados, Serie documental electoral 2, $\mathrm{n}^{\circ} 8$. 
Vicario Eclesiástico de Alcaraz y Valladolid de Infantes, se hallaron con la novedad de que sin haberse presentado todos los testimonios ni aún haberlos recibido del escribano D. Blas Francisco Leal los Diputados de Alcaraz, tomaron la voz dos abogados, el uno que no conoce el exponente y el otro el Diputado D. Francisco Cenón e Hinojo, y claramente sin el menor rebozo propusieron que estando la provincia tan escasa de hombres de ilustre talento y haberes, nada mejor se podía hacer que desde luego nombrar para vocales de Cortes al señor Intendente, y aquí hicieron su panegírico a los señores Melgarejo y Giraldo, y aquí les hicieron el suyo al señor cura de San Salvador de Madrid y aquí encarecieron esta circunstancia, el primer sustituyente al señor Prior de Herencia, y añadieron que si los señores Diputados convenían como era regular, se extenderían las actas y nada más había que trabajar.

Extrañaron tan descarada propuesta, aunque sabían era hija de un antiguo y premeditado plan, el exponente y el cura de la Puebla de Almoradiel...”

La Junta electoral la componían: Gerónimo Salvador de Velasco, secretario; Juan Bautista Erro y Azpiroz, intendente general de la provincia de La Mancha; José Ortiz de Pinedo, vicario del partido de Alcaraz; Luis de Ulloa, teniente coronel de los Reales Ejércitos, gobernador militar y político de la villa y partido de Infantes; y José María García Valladolid, abogado de los Reales Consejos.

Acudieron los representantes de los partidos judiciales de Alcaraz, Infantes y Alcázar de San Juan y faltaron los de Ciudad Real que no pudieron trasladarse por estar ocupadas sus tierras por los franceses. Los 12 representantes que tomaron parte en la votación fueron:

Partido de Alcaraz:

1. Juan de Lera y Cano, natural de Peñas de San Pedro, cura de San Salvador de Madrid.

2. Gerónimo Sanz Calvo, cura de Ayna.

3. Antonio Fernández Riesco, cura de Cotillas.

4. Francisco Cenón Hinojo, abogado de los Reales Consejos. Vecino de Bienservida.

Partido de Infantes:

5. Sebastián Rodríguez Romero, cura de Santa Cruz de los Cánamos.

6. Juan Martín Jiménez, cura de la Puebla del Príncipe.

7. Estanislao Fontes Abad, vecino de Villahermosa.

8. Antonio José Cabañero, abogado de los Reales Consejos, vecino de Villanueva de los Infantes. Fue presidente de la Junta Local de Defensa de Villanueva de los Infantes. El 7 de marzo de 1809, la 
Junta Superior de La Mancha se queja a la Junta Central de los abusos con la renta y las armas, de la Junta Local de Infantes. El Sr. Cabañero fue desterrado.

Partido de Alcázar de San Juan:

9. Pedro Félix Cano, cura de Almoradiel.

10.Manuel González de Salcedo Cano, presbítero de hábito de San Juan y cura prior de Herencia.

11.Domingo María Tordera, presbítero de hábito de San Juan y cura prior de Santa Quiteria de Alcázar de San Juan.

12. Carlos Herreros, abogado de los Reales Consejos, vecino de Argamasilla de Alba.

Los diputados que resultaron elegidos el día 16 de agosto de 1810 en Riopar fueron:

Juan Bautista de Erro y Azpiroz, Fernando Melgarejo de los Cameros, Ramón Giraldo y Arquellada y Juan de Lera y Cano. Como suplente, Manuel González de Salcedo.

Atendidas las protestas de Gerónimo Sanz Calvo, el 15 de septiembre de 1810 la Comisión de Alistamiento y Elección a Cortes anulaba la designación de Juan Bautista de Erro por no ser natural de la provincia de La Mancha y le ordenaba que no se presentara en la ciudad de Cádiz. El 25 de septiembre de 1810 se elegía en la Isla de León, entre los refugiados procedentes de la provincia, a Mariano de Blas Garoz y Peñalver para sustituir al señor Erro y Azpiroz ${ }^{3}$.

\section{Diputados elegidos en 1810 POR la PROVINCIA de La MaNCHa QUe FINALMENTE FIRMARON LA CONSTITUCIÓN DE 1812}

- Ramón Giraldo y Arquellada (1767-1849):

Obtuvo 12 votos. Natural de Villanueva de los Infantes. Tuvo una vida apasionante, agitada y azarosa. Sacrificó su salud, su familia y su patrimonio en defensa de los principios liberales, siendo víctima del despotismo, la injusticia y la intriga.

Fue político y jurista, diputado y presidente de las Cortes en varias ocasiones, regente de la Audiencia de Valladolid, fiscal del Consejo de Navarra, consejero del Rey, oidor de la Real Audiencia de Valencia, miembro del Tribunal de Cuentas, subdelegado de Fomento en la provincia de Albacete y Magistrado y Presidente del Tribunal Supremo de Justicia.

3 Archivo del Congreso de los Diputados, Serie General, leg. 124, nº 23. 
Nació el 28 de abril de 1767 en Villanueva de los Infantes (provincia de La Mancha)4. Fue bautizado el 2 de mayo de 1767 en la Iglesia Parroquial de San Andrés por el cura teniente Sebastián José Martínez y Morales con el nombre de Ramón Tomás de Aquino, Prudencio, Vidal, Rafael, Antonio, Atanasio y Mariano de los Dolores García-Giraldo Arquellada. Fue padrino Juan Miguel García Giraldo Arquellada, hermano del bautizado. Fue confirmado el 30 de octubre de 1771 en la Iglesia de San Andrés de Villanueva de los Infantes por el obispo de Constanza Felipe Pérez de Santa María. Falleció en Madrid el 29 de marzo de 1849.

Sus padres eran Miguel García Giraldo, natural de Villanueva de los Infantes y su madre Luisa Arquellada ${ }^{5}$. Sus abuelos paternos, Juan García Giraldo y Tomasa Muñoz de Cuerda, naturales de Villanueva de los Infantes. Sus abuelos maternos, Cristobal Arquellada y Berrio, de Madrid y María Sacristán, natural de Orán ${ }^{6}$. Su padre, Miguel García Giraldo, fue alcalde mayor de Cieza, Uclés, Quintanar, Totana y Moratalla.

Instruido en Humanidades, fue admitido en el Seminario Conciliar de Murcia donde cursó tres años de filosofía. Obtuvo el grado de Bachiller en Artes por la Universidad de Baeza. Estudió 6 años de Derecho Civil y Canónico en la Universidad de Orihuela finalizando el 5 de junio de 1785. En agosto de 1782 residía en Jumilla. Se trasladó a la Corte Madrileña donde asistió como pasante de Juan Manuel Vélez de las Cuevas, abogado de los Reales Consejos y del Ilustre Colegio de Madrid desde el 15 de junio de 1785. Mientras tanto continuó su formación en los Reales Estudios de San Isidro de Madrid, durante un año en Derecho Natural y de Gentes y dos años de Disciplina Eclesiástica, Liturgia y Ritos Sagrados. Fue examinado y aprobado para ejercer como abogado el 23 de marzo de 17897.

Desarrolló una brillante carrera profesional en los siguientes destinos: relator del Consejo de Ordenes desde el 11 de diciembre de 1792 hasta el 27 de marzo de 1795; fiscal del Consejo de Navarra desde el 8 de agosto de 1802; oidor de la Audiencia de Valencia desde el 23 de

4 En 1774 nació otro Ramón Giraldo en Villanueva de los Infantes. En el libro de bautismos $\mathrm{n}^{\circ} 23$ (1814-1824) de la Iglesia de San Andrés de Villanueva de los Infantes, figura la inscripción del bautizo el 29 de junio de Luciana María Juana, hija de Ramón Giraldo de 40 años y de oficio labrador y de Felipa Castellano de 28 años, ambos de Infantes, nacida el 26 de junio.

5 El origen de su madre no está claro, por un lado en el libro de bautismos parece deducirse que era natural de la villa de Zuza en Navarra, región donde además existe este apellido y por otro en la transcripción de la partida de bautismo que existe en el Archivo Histórico Nacional, figura como lugar de nacimiento, Cieza en Murcia, donde su padre ocupó algunos cargos.

6 Archivo Parroquial de la Iglesia de San Andrés de Villanueva de los Infantes. Libro de bautismos 1765-1773, folio 100 .

7 Archivo Histórico Nacional, Consejos, 12148, exp. 7, Ministerio de Justicia, Jueces 4454, exp. 3155 . 
mayo de 1809; ministro del Supremo Tribunal de Justicia desde el 20 de mayo de 1820 hasta octubre de 1823; regente de Valladolid desde el 29 de abril de 1834; ministro del Supremo Tribunal de España e Indias y miembro del Consejo Real en la sección de Gracia y Justicia desde el 4 de agosto de 1834; y visitador de las cárceles de la Corte desde el 8 de octubre de 1834.

Tenemos constatación de diversos domicilios durante sus estancias en Madrid. En 1794 vivía en la calle del Caballero de Gracia, en 1796 en la calle del Espejo, de 1797 a 1802 en la calle de la Concepción Gerónima, en 1835 en la calle Fuencarral y a partir de 1837 en la calle de la Villa.

En abril de 1808 tuvo el honor de estar en Bayona al mismo tiempo que sus majestades los reyes de España desempeñando delicados encargos con fidelidad y patriotismo. Salió de Bayona con grandes riesgos y se trasladó a Pamplona donde fueron terribles los compromisos en que se halló por no querer contribuir y si oponerse, clara y decididamente al reconocimiento del intruso gobierno y a la proclamación que querían los franceses se ejecutase del que llamaban Rey, llegando las cosas al extremo de tener que escapar muy a la ligera en agosto de 1808 hacia Agreda, abandonando y perdiendo todo cuanto tenía en su casa.

Después marchó entre grandes incomodidades a pie y en carro hasta Valencia acompañado de su mujer y una hija de corta edad, de las dos hijas huérfanas de Marcos López de Gonzalo, oidor del Consejo de Navarra y de la familia de Juan Antonio Morales, alcalde del Tribunal de la Corte, fallecido en el camino. En otoño de 1808 llegaron todos a Valencia sin más pertenencias que la ropa que llevaban puesta.

En mayo de 1809, vacante una plaza de oidor de la Audiencia de Valencia y ante la imposibilidad por los avatares de la guerra de volver a Pamplona, fue nombrado para ese cargo. El 13 de marzo de 1810 solicitó una licencia de cuatro meses para restablecer su salud y tomar baños en Murcia junto a su mujer. La licencia fue concedida el 15 de junio de 1810.

El día 16 de agosto de 1810 fue elegido con doce votos diputado por la provincia de La Mancha, en las Reales Fábricas de Latón de San Juan de Riopar, cuando parte de la provincia estaba todavía en manos de los franceses. El 24 de noviembre de 1810 se encontraba ya cerca de un mes en Alicante junto a los diputados Mateo López de Cuenca y Vicente Pascual de Teruel esperando un barco que los trasladase a la Isla de León.

El 2 de febrero de 1811, las Cortes Generales y Extraordinarias aprobaron sus poderes y el 4 de febrero prestó juramento. Tuvo el honor de presidir las Cortes de Cádiz desde el 24 de agosto al 23 de septiembre de 1811, periodo en el que se comenzó a discutir el proyecto formado para el arreglo y mejora de la Constitución política de la Nación española que finalmente fue promulgada el 19 de marzo de 1812. 
El 24 de agosto de 1811 al ocupar la silla como presidente de la cámara entre otras cosas dijo:

“..Suplico, pues, a V.M., y a mis dignísimos compañeros en particular, que me auxilien, para que en este mes, que será el más largo que cuente en mi vida, se manifieste que todavía existe la circunspección española, y que la conservación de nuestra santa religión, la salvación de nuestra afligida Patria y la restitución al trono de nuestro amado Monarca, el señor D. Fernando VII, son los únicos objetos que nos han reunido."

El 25 de agosto de 1811 inició con estas palabras el período de discusión del proyecto de Constitución:
"Señor, ha llegado felizmente el deseado día en que vamos a ocu- parnos en el más grande y principal objeto de nuestra misión. Hoy se empieza a discutir el proyecto formado para el arreglo y mejora de la Constitución Política de la Nación Española y vamos a poner la primera piedra del magnífico edificio que ha de servir para salvar a nuestra afligida Patria, y hacer la felicidad de la Nación entera, abriéndonos un nuevo camino de gloria... Empecemos pues la grande obra, para que el mundo entero y la posteridad vean siempre que estaba reservado solo a los españoles mejorar y arreglar su Consti- tución, hallándose las Cortes en un rincón de la Península, entre el estruendo de las armas enemigas, combatiendo con el mayor de los tiranos, cuya cerviz se humillará más con este paso que con la des- trucción de sus ejércitos...”.

Participó en las siguientes comisiones: de poderes, causas atrasadas, justicia, presidente de las Cortes, protesta del obispo de Orense, reglamento del Poder ejecutivo, organización del Gobierno, de honor, Tribunal de Hacienda, imprenta, infracción de Constitución y especial.

Realizó discurso sobre los siguientes asuntos: formas en Ultramar, esclavitud de Puerto-Rico, alistamiento, visita de cárceles, causa de infidencia, servicios de la división Mina, plan de Hacienda, mando de los ejércitos, competencias judiciales, cruces de Carlos III, libertad de comercio, capitulación de Badajoz, abolición del tormento, Junta Suprema de Guerra, representación de San Clemente, secretaría de la Estampilla, Colegio de Abogados de Cádiz, reglamento de justicia, causa del coronel Cumplido, representación de la Junta de La Mancha, jubilaciones y cesantías, clasificación de empleados, petición de la Junta de Valencia, reglamento de policía, señoríos, reglamento de guerrillas, 
discurso de gracias. Como Presidente, proyecto de Constitución, exposición del consulado de Méjico, discurso con motivo del aniversario de la instalación de las Cortes, causa del ex-Regente Sr. Lardizábal, limitación de las prerrogativas regias, representación del Sr. Cano Manuel, causas pendientes, reglamento de montes, organización del Gobierno, elogios de la división del brigadier Mina, juramento, remoción de magistrados, tribunales especiales, repartimiento de baldíos, confiscos y secuestros, libertad de imprenta, audiencias y juzgados, méritos del brigadier Curuchaga, derrota de Castalla, empleados del Gobierno intruso, elección de ayuntamientos, Tribunal de Hacienda, abolición de la Inquisición, restablecimiento de conventos, pleitos fenecidos, responsabilidad judicial, reglamento de la Regencia, agricultura, conducta del cabildo eclesiástico de Cádiz, incompatibilidades parlamentarias y recurso de nulidad.

Apoyó la tesis liberal que eran las Cortes quienes, siempre desde una postura regalista, deberían asumir las competencias para conocer en los recursos de fuerza establecidos por el Concilio de Trento; y expuso sus ideas sobre las diferencias habidas entre la representación nacional y la popular.

También se ocupó de los asuntos que afectaban a la provincia de La Mancha. El 11 de marzo de 1811 leyó una comunicación de la Junta Superior de La Mancha quejándose de las vejaciones y tropelías que los pueblos y las gentes de la provincia estaban sufriendo por parte del Comandante de la columna volante, el brigadier Osorio y las tropas a su mando. En la sesión del 20 de julio de 1813, presentó una exposición del ayuntamiento constitucional de Membrilla aprobada el 11 de julio en la que felicitaba al Congreso por la abolición de la Inquisición, los señoríos y otros decretos benéficos, al tiempo que solicitaba a la Regencia del Reino sobre el origen y destino de la contribución conocida como "Merced de amigos" que únicamente pesa sobre la apreciable clase de los labradores".

En mayo de 1815 estando en Valencia, fue requerido para viajar a Madrid, pero solicitó la exoneración de dicho viaje por falta de salud. Después del Pronunciamiento de Riego fue nombrado en mayo de 1820, ministro del Supremo Tribunal de Justicia.

El 21 de mayo de 1820 fue elegido diputado por la provincia de La Mancha por la Junta Electoral reunida en la Iglesia Nuestra Señora del Prado de Ciudad Real junto a Luis López del Carrillo y Diego Medrano. Tomó posesión el 1 de julio. Fue presidente de la Cámara desde el 9 de agosto de 1820 hasta el 8 de septiembre de 1820 y del 28 de enero de 1822 hasta el 14 de febrero de 1822 .

Diario de Sesiones del 20 de julio de 1813 y diario El Conciso, miércoles 21 de julio de 1813. 
El 11 de octubre de 1822, siendo viudo y viviendo en Madrid, solicitó una licencia para contraer matrimonio con María Josefa López de Gonzalo, hija legítima de Marcos López de Gonzalo, oidor del extinguido Consejo de Navarra y de Ildefonsa de las Heras (ambos difuntos). Como vimos anteriormente, María Josefa López, mucho más joven que Ramón Giraldo, fue una de las que le acompañaron en su viaje hasta Valencia en otoño de 1808. La licencia fue concedida el 15 de octubre de 1822 y posiblemente el matrimonio se pudo celebrar poco después.

La llegada a España de los Cien Mil Hijos de San Luis para restablecer el absolutismo, supuso para Ramón Giraldo el inicio de un proceso de impurificación y retiro forzoso en Torre de Pedro Gil (Torreperogil, en Jaén) desde octubre de 1823 y posteriormente en Torre de Juan Abad desterrado por Calomarde, alojado en la mismísima casa de Quevedo. Durante su estancia, fue mayordomo de José Bustamante y Quevedo, dueño de la jurisdicción de la Torre, por encargo de Fernando Calderón de la Barca $^{9}$. En este periodo sufrió toda clase de privaciones viviendo en la mayor indigencia al dejarle con tan solo la mitad del sueldo, 6.300 reales, de los 12.000 que le correspondían como fiscal jubilado del Consejo de Navarra.

El 26 de julio de 1829 dirigió una carta desde Torre de Juan Abad, en la que solicitaba se le abonasen, por la Intendencia de La Mancha, las dos terceras partes de la asignación que le correspondía. En 1830 se denegó su solicitud ofreciéndonos la contestación algunos datos importantes sobre la consideración que el gobierno absolutista tenía de Ramón Giraldo:

"La conducta de D. Ramón no ofrece hechos particulares con que recriminarlo sino merecían este nombre los cargos de Diputado y Presidente de las Cortes, que desempeñó varias veces, añadiendo alguno que sus ideas y sentimientos eran bastante racionales, aunque algo inclinados a aquel orden de cosas, que sin duda por esa razón se dio a conocer más por la clase de destinos que desempeñó que por la exageración de su opiniones".

Trasladado a Madrid después de morir Fernando VII, en mayo de 1833 se le restituyeron los 12.000 reales que le correspondían de pensión, pero en junio de 1834 todavía no se le habían abonado. En febrero de 1834 fue nombrado Subdelegado de Fomento ${ }^{10}$ de la provincia de

9 J. Jiménez Ballesta, Torre de Juan Abad en su historia, la huella de Quevedo, Madrid, Ayuntamiento de Torre de Juan Abad 2011, p. 180.

10 Desde la Constitución de 1812 el Jefe Político, o Jefe Superior, nombrado por el Rey gobernaban las provincias y, desde la creación de las diputaciones, fueron sus presidentes. Por Real 
Albacete y como tal organizó y dirigió el 4 de mayo de 1834 en la capital manchega los actos de proclamación de la Reina Isabel II:

\begin{abstract}
"EI día 4 del corriente, ha sido para el vecindario de Albacete el día mas clásico que cuenta entre los de su historia, pues como capital de una nueva provincia, ha celebrado en él con la mayor solemnidad el acto de la proclamación de nuestra inocente y excelsa Reina Doña Isabel II. Es imposible dar una idea de las fiestas y regocijos que ha habido con motivo tan plausible. Funciones de iglesia, novillos, bailes, fuegos artificiales, comidas y socorros á los pobres, libertad á encarcelados; nada se ha perdonado en celebridad de tan fausta circunstancia, en laque embriagados de entusiasmo los vecinos de Albacete han reconocido y jurado por su Reina á la que acaba de enjugar nuestras lágrimas y cicatrizar nuestras heridas. Todas estas fiestas han sido dirigidas por el respetable subdelegado de Fomento D. Ramón Giraldo, tan conocido en toda la España por sus talentos y virtudes, que supo muy bien lucir durante su permanencia en las cortes como diputado; pero si todo ha llamado la atención en las fiestas, puede asegurarse con verdad que el regocijo llegó á su colmo cuando dicho Don Ramón Giraldo se presentó en ellas al público con el sencillo uniforme de catador Urbano. Este golpe de su política ha acabado de cautivar los corazones de todos, y ha dado el mayor impulso á el alistamiento de la Milicia Urbana" ${ }^{11}$.
\end{abstract}

El 20 de mayo de 1834 fue elegido por la Junta Electoral celebrada en la capital, diputado por la provincia de Ciudad Real junto a Diego Medrano, José Vicente Baíllo, Manuel Abad y Sandoval. Renunció al cargo el 7 de agosto de 1834 por falta de renta. En su escrito de renuncia relata que las dos fincas que posee en Villanueva de los Infantes y Alcubillas no alcanzan el valor de 12.000 reales por el deterioro y abandono sufrido al estar ausente de su pueblo natal desde la más tierna edad, por los empleos y cargos públicos que ha desempeñado y las persecuciones que ha sufrido.

El 2 de enero de 1837, pronunció en el Supremo Tribunal de Justicia, del que era Decano un discurso en el que además de exhortar al cumplimiento de sus deberes a los jueces, realizó toda una declaración política al recordar a los que:

Decreto de 23 de octubre de 1833 se establecieron los jefes provinciales, con el título de subdelegados de Fomento, encargados de estudiar las necesidades locales y de socorrerlas, una figura análoga a la de Gobernador Civil. Sus funciones versaban sobre diversos asuntos.

11 La Revista Española, 15 de mayo de 1834. 
"han arrostrado peligros de todas clases, desde el año 1808, para llenar sus funciones y defender la independencia nacional; los que en las Cortes de 1812, 1820, 1822 propusieron, votaron y sostuvieron las justas medidas y reformas en bien de la patria, y que por tan distinguidos servicios han sido víctimas, sufriendo impurificaciones, persecuciones y toda clase de disgustos; los que en las actuales Cortes han merecido la confianza de sus provincias y corresponden tan dignamente a ella; y finalmente, los que habiendo desempeñado encargos públicos en los diez años de amarga memoria, se han conservado justos y fieles sin apostatar de los principios que una vez juraron" ${ }^{12}$.

En 1841 le fue concedida la Gran Cruz de la Orden de Carlos III junto a José María Calatrava y a Miguel Antonio de Zumalacárregui. Esta distinción mereció un artículo descalificativo del periódico El Nacional:

"Hola, hola, los progresistas, los demócratas, los enemigos de los abusos y odiosos privilegios, los que desprecian cruces y distinciones, los que promueven o apoyan revoluciones en sentido popular. Tan vanos, tan aristócratas, tan amigos de bandas, declaraciones y bordados. Y querrán todavía negarnos que lo mismo son unos que otros los corifeos de los partidos"13.

Presidente interino de la Cámara de Diputados desde el 3 de abril de 1843 hasta el 30 de abril de 1843. El 30 de julio de 1843 el Gobierno encargó interinamente la presidencia del Supremo Tribunal de Justicia a Ramón Giraldo. En agosto de 1845 fue nombrado Senador Vitalicio por la reina Isabel pero no llegó a tomar posesión al renunciar al cargo.

El 30 de marzo de 1849 su hija Dolores y su nieto José Antonio Gutiérrez comunican al Ministerio de Justicia, el fallecimiento en Madrid, la noche anterior de Ramón Giraldo y Arquellada. Es posible que fuera enterrado en el cementerio de la Sacramental de San Ginés y San Luis de Madrid. De su muerte se hicieron eco varios periódicos, El Observador, el 31 de marzo, La Época y El Clamor Público, el 1 de abril, o El Genio de la Libertad, el 12 de abril:

"Con dolor anunciamos á nuestros lectores la sensible pérdida del antiguo y virtuoso magistrado D. Ramón Giraldo, cuyas bellas prendas como juez y como ciudadano tuvieron ocasión de apreciar cuantos le trataron de cerca. La magistratura española ha perdido en este

12 Biblioteca Nacional VC/2522/53.

13 El Nacional, 3 de abril de 1841. 
respetable octogenario, uno de sus mas ilustres individuos, el partido progresista uno de sus más consecuentes adalides, y la nación uno de sus mas apreciables hijos. ¡Séale la tierra leve!”.

El 16 de mayo de 1849 El Clamor Público publicó un amplio artículo con motivo de las honras fúnebres celebradas en honor de Ramón Giraldo en Albacete:

"Se han celebrado en esta con toda la pompa y solemnidad posibles, las honras fúnebres por el alma del Excmo e Ilmo Sr. D. Ramón Giraldo, ministro decano que sido del Tribunal Supremo de Justicia”.

Sus numerosos amigos, ya que no podían restituirle la vida, determinaron ofrecerle este testimonio del cariño que le tenían, esta demostración de reconocimiento a los particulares servicios que prestara a la provincia y esta prueba de admiración a sus ínclitas virtudes. Deseosos de que este acto religioso tuviera una solemnidad que lo distinguen de todos los otros, se colocó en el centro de la Iglesia Parroquial Castrense, un catafalco de cinco cuerpos en cuya cúspide se colocó una urna y sobre ella la toga y demás distinciones de la magistratura, con la banda de la Gran Cruz de Carlos III, a cuya orden correspondía el difunto. En los diferentes cuerpos del catafalco, además de una iluminación extraordinaria y de cuatro pisos en sus ángulos, se veían diferentes inscripciones que recordaban los muchos altos cargos que desempeñó el ilustre difunto y varias alegorías que representaban las más importantes de estas.

La función religiosa ha sido más solemne todavía de la que la localidad permitía y la concurrencia tan numerosa y distinguida como no se vio jamás en otra alguna. Tanto la clase media cuanto la aristocracia, cuanto el sexo hermoso, han concurrido de porfía, distinguiéndose los señores regente, magistrados, y fiscal de la audiencia, los cuales y sus familias, así como todos los subalternos, han convenido al acto haciéndolo también el juez de primera instancia, abogados, fiscales, promotor fiscal, decano y abogados del ilustre colegio, dos consejeros provinciales, y varios empleados y oficiales de la guarnición.

Una comisión compuesta de tres exdiputados a cortes, de dos magistrados y un juez de primera instancia cesantes, de dos abogados, un propietario, un comerciante, el subdelegado de medicina, el vicario eclesiástico y el cura castrense, que representaba a la familia, tenía dispuesto que un individuo de su seno pronunciara, en elogio del difunto, un discurso acomodado a la naturaleza del acto y a su objeto, y de muy buen grado hubiera cumplido esta misión el encargado de ella, si por razones de prudencia no hubiesen aconsejado desistir de este pensamiento. 
Entre los individuos de esta comisión llamaba la atención el Sr. D. Francisco Sánchez Castilla, ministro jubilado de esta audiencia, el cual, aunque impedido hace algunos meses por su avanzada edad y sus dolencias, se hizo llevar a la parroquia para dar esta muestra de su afecto al que ero hoy objeto del común sentimiento.

De esta manera ha dado el pueblo de Albacete un solemne testimonio del aprecio que tiene a aquellas autoridades que supieron con su comportamiento captarse benevolencia general, y de este modo ha revelado todo el respeto con que contemplaba al que después de haber desempeñado en el parlamento y en la magistratura, los más importantes y elevados cargos, ha muerto pobre como se decía en una de sus inscripciones de su túmulo. Esta especie de ovación que en vida del $\mathrm{Sr}$. Giraldo hubiera podido traducirse por una liviana adulación, es hoy, cuando ya no existe ese distinguido patricio, probo y sabio magistrado, el mejor comprobante del influjo que todavía conserva la virtud sobre un pueblo que solo a ella tributa tan noble y tan significativo homenaje".

Trayectoria de Ramón Giraldo Arquellada como diputado en el Congreso:

\begin{tabular}{|c|c|c|c|c|}
\hline Año de elección & Provincia & Elección & Alta & Baja \\
\hline 1810 & La Mancha & $16-08-1810$ & $02-02-1811$ & $20-09-1813$ \\
\hline 1820 & La Mancha & $21-05-1820$ & $01-07-1820$ & $14-02-1822$ \\
\hline 1834 & Ciudad Real & $30-06-1834$ & $22-07-1834$ & $09-08-1834$ \\
\hline 1843 & Albacete & $27-02-1843$ & $18-04-1843$ & $26-05-1843$ \\
\hline
\end{tabular}

Presidente del Congreso de los Diputados:

\begin{tabular}{|c|c|}
\hline Toma de posesión & Cese \\
\hline $24-08-1811$ & $23-09-1811$ \\
\hline $09-08-1820$ & $08-09-1820$ \\
\hline $28-01-1822$ & $14-02-1822$ \\
\hline $03-04-1843$ & $30-04-1843$ \\
\hline
\end{tabular}

- Fernando Melgarejo de los Cameros (1738-1816):

Consiguió doce votos. Liberal Moderado. Natural de Villanueva de los Infantes, político y jurista. Diputado en la Cortes Generales y Extraordinarias que redactaron y aprobaron la Constitución de 1812, fue regente del Real Consejo de Navarra y Honorario del Real y Supremo de Castilla. 
Nació en Villanueva de los Infantes el 21 de noviembre de 1738. Fue bautizado en la parroquia de San Andrés el 28 de noviembre de 1738 como Fernando Manuel. Era hijo de Antonio Tomás Melgarejo y Mesto, natural de Castillo de Garcimuñoz y de Inés Matea de los Cameros y Camino, natural de Mula en Murcia, ambos residentes en Villanueva de los Infantes. Fue padrino en el bautizo, su hermano Francisco Gonzalo Melgarejo de los Cameros, caballero de la Orden de San Juan ${ }^{14}$. Murió soltero en Villanueva de los Infantes, el 28 de enero de $1816^{15}$.

Desde su juventud se dedicó al estudio de las ciencias y particularmente de la jurisprudencia civil y canónica, que cultivó con éxito en las universidades de Almagro, Valladolid, Salamanca y Alcalá, donde obtuvo por oposición una beca de jurista del colegio mayor de San Ildefonso en 1762.

Desde 1749 estudió tres cursos de artes en el Convento de Nuestra Señora del Rosario de la Universidad de Almagro. Del 8 de noviembre de 1752 al 2 de enero de 1757, cursó, ganó y aprobó cinco cursos en las Facultades de Cánones y Leyes de la Universidad de Alcalá recibiendo el grado de Bachiller en Cánones. Trabajó como pasante en la academia teórico-práctica de Juan de Uría, abogado de la Chancillería de Valladolid ${ }^{16}$.

Dada su incipiente y brillante carrera profesional, fue nombrado alcalde de la Corte Mayor del Consejo de Navarra. En el año 1793 fue promovido a oidor del citado Consejo, en 1795 a consultor de guerra de la Capitanía General de aquel reino y posteriormente a regente del Consejo de Navarra en cuyo empleo se hallaba al tiempo de la invasión francesa.

Requerido por un comisionado de José Bonaparte para que prestase juramento de fidelidad, se negó a ello teniendo que abandonar su casa retirándose con evidente peligro de su vida a las montañas de Aragón. Reducido a la situación de una vida errante y noticiosos los manchegos de la suerte de su digno paisano, le nombraron diputado para las Cortes Generales y Extraordinarias, convencidos de su esmero para poner fin a los desastres de la nación, restaurando en el trono a su soberano Fernando VII. Su delicada salud, avanzada edad y los peligros del viaje a Cádiz no fueron bastante para hacerle vacilar un momento y trasladado al Congreso manifestó constantemente su decidido amor al Rey y a la patria. En marzo de 1810 se encontraba en San Clemente. El 26 de octubre de 1810 se incorporó a la Cámara y prestó juramento.

14 Archivo Parroquial de la Iglesia de San Andrés de Villanueva de los Infantes. Libro de bautismos 1731-1744, folio 23 .

15 Archivo Parroquial de la Iglesia de San Andrés de Villanueva de los Infantes. Libro de defunciones 1811-1828, folio 111.

16 AHN, Ministerio de Justicia, Jueces 4681, exp. 6093. 
Formó parte de la comisión encargada del examen de las operaciones de los ex regentes durante su Gobierno, compuesta por seis diputados. Propuso que no tuvieran acceso a ciertos altos empleos, como regentes del Reino o secretarios del Despacho, todos aquellos que hubieran prestado juramento al rey José I. Las Cortes acordaron que, una vez que se clausuraran sus sesiones, se reintegrara a su cargo de regente de la Audiencia de Navarra con derecho a percibir los sueldos de regente de la misma, en compensación por haberse fugado de la misma y haberse negado a colaborar con los franceses en 1808 .

Durante su estancia en Cádiz vivió en la calle Calvario num. $134{ }^{17}$. Tuvo un accidente al volcarse el carruaje donde viajaba. Sufrió heridas y contusiones en la pierna derecha que lo postraron en la cama. A finales de 1813 regresó a Villanueva de los Infantes. En marzo de 1814 su salud no había mejorado tal como certificó Esteban González, cirujano titular de Villanueva de los Infantes.

Participó en la Comisión de las Operaciones de los ex-Regentes y realizó discursos sobre los siguientes asuntos: dimisión del obispo de Cuenca, reglamento del Consejo de Regencia, coristas en quinta, solicitud del Marqués del Palacio, representación de San Clemente, del Sr. Colon, limitación de las prerrogativas regias, audiencias y juzgados.

Solicitó en marzo de 1814 el abono de la pensión que le correspondía como regente de Navarra, dada la indigente necesidad en que se hallaba por los suministros hechos a los Reales Ejércitos y por la rapacidad del enemigo hacia sus bienes y propiedades en Infantes y en Pamplona. En 1815 se le concedió una pensión de 41.500 reales como premio de S.M. a sus servicios y lealtad, con la jubilación y honores del Real y Supremo Consejo de Castilla.

En julio de 1816 la Gaceta de Madrid, refiriéndose a Fernando Melgarejo, apuntaba: Concluyó sus días siendo modelo de honor, virtud, caridad y patriotismo ${ }^{18}$.

- Juan Nepomuceno de Lera y Cano (1755-1831):

Obtuvo diez votos. Nació en Peñas de San Pedro el 26 de febrero de 1754. Presbítero, doctor en Teología por la Universidad de Orihuela, fue párroco de Cenicientos, La Guardia y el Salvador de Madrid. Llegó a ser obispo de Barbastro y Segovia ${ }^{19}$.

17 www.cadiz2012.es

18 Gaceta de Madrid, no 89 (18-7-1816).

19 F. Candel Crespo, "Tres obispos albacetenses en la España de Fernando VII", en Al-Basit, $n^{\circ} 35$ (1994), pp. 113-132. 
Liberal moderado, juró su cargo como diputado en las Cortes Generales y Extraordinarias de Cádiz el 25 de octubre de $1810^{20}$. Formó parte de una sola comisión, la de prebendas eclesiásticas, y participó en debates sobre diez cuestiones diferentes destacando los de señoríos, Inquisición, proyecto de Constitución. Se opuso al principio de soberanía nacional, negando, de acuerdo con los clásicos de los siglos XVI y XVII, la capacidad de la sociedad para elegir su propia forma de gobierno.

Con la reacción absolutista de Fernando VII, fue nombrado obispo de Barbastro, en 1814, y consiliario bienal eclesiástico de los Reales Hospitales, en 1815. En 1828 era obispo de Segovia, donde murió el 23 de enero de 1831.

- Mariano de Blas Garoz y Peñalver (1758-1830)

Político absolutista y militar. Prestó juramento como diputado el 10 de octubre de 1810. Nació en Los Yébenes el 24 de septiembre de 1758. Pasó su infancia en Mora y después marchó a Madrid a cursar estudios $^{21}$. Fue enterrado el 17 de abril de 1830.

Desarrolló una brillante carrera política y militar. Oficial Primero de la Secretaria de Estado y del Despacho de Guerra, secretario de su Majestad con ejercicio de Decretos, teniente coronel de los Reales Ejércitos y consejero honorario del Supremo Consejo de la Guerra.

También fueron elegidos diputados por la provincia de La Mancha y no llegaron a tomar posesión:

- Juan Bautista de Erro y Azpiroz (1773-1854):

Sumó doce votos y fueron revocados sus poderes. Nació en Andoaín el 21 de julio de 1774. Hijo de Martín de Erro y Larrea y de Rafaela Azpiroz $^{22}$. Fue intendente de La Mancha y presidente de la Junta Superior de Defensa de La Mancha durante la Guerra de la Independencia, superintendente de las minas de Almadén, caballero de la Orden de Carlos III, secretario de Hacienda y consejero de Estado.

Como sabemos resultó elegido el 16 de agosto de 1810 diputado propietario para las Cortes Generales y Extraordinarias por el procedimiento para las provincias ocupadas por los franceses. Al día siguiente envió una carta al Secretario de despacho universal de hacienda en la que manifestaba que había intentado excusar su nombramiento. Aún así se dirigió al puerto de Cartagena para embarcarse con los demás diputados de Levante con destino a la Isla de León. Allí coincidió y conoció, que a Francisco Antonio de la Dueña y Cisneros, obispo de Urgel y al

20 ACD, Serie documental electoral: $2, \mathrm{n}^{\circ} 8$.

21 AHN, FC-Ministerio de Hacienda, 1236, Exp.7-1.

22 AHN, Estado Carlos III, exp.1904. 
capitán general de Valencia, se les había excluido del Congreso por no ser naturales de las provincias donde habían sido elegidos y hallándose él en el mismo defecto, volvió a su destino como intendente de La Mancha. Las Cortes efectivamente anularon su elección por no ser natural de la circunscripción y el 25 de diciembre de 1810 denegaron su solicitud para otorgarle un documento que acreditara tal circunstancia.

Hombre de marcadas ideas absolutistas, a pesar de su agitada vida pública y política, tuvo tiempo para el estudio llegando a ser considerado como un erudito experto en la lengua vaca. Se casó con María del Carmen Costantín y tuvo al menos dos hijos, Mateo y Juan Evangelista ${ }^{23}$.

Empezó sus estudios en el Liceo o Seminario de Vergara, donde su padre era profesor. Dominaba a la perfección la lengua castellana y latina. Publicó varios libros sobre lenguas primitivas de España.

Después de ser guardia de corps ${ }^{24}$, pasó el 17 de abril de 1791 a trabajar en las minas de Almadén donde trazó sus planos y participó en su Academia de Minería y Geometría Subterránea ${ }^{25}$. El 25 de junio de 1798 fue designado contador de rentas reales de la provincia de Soria. En 1807 fue nombrado para servir la Contaduría General de Propios y Arbitrios y Rentas Reales de la provincia de La Mancha.

Desde el inicio de la Guerra de la Independencia formó parte de la Junta Superior de La Mancha con sede inicial en Ciudad Real y luego por las vicisitudes de la contienda en Santa Cruz de Mudela, La Carolina, Elche de la Sierra y Villanueva de los Infantes, de la que fue nombrado presidente el 20 de diciembre de 1809.

El 13 de mayo de 1810 en plena ocupación francesa, redactó en Alcaraz como Intendente de la provincia de La Mancha esta proclama ${ }^{26}$ :

"Generosos pueblos de La Mancha:

El Gobierno Supremo de la Nación, celoso de vuestro bien ha enviado autoridades a vuestra provincia para que os dirijan y os aúnen contra el enemigo común. Unid vuestras fuerzas y huid de los pueblos para incorporaros en el estandarte de la nación que se enarbola en medio de vosotros para proteger la santa religión, defender vuestros hogares y libertaros de la esclavitud que os amenaza... Alarma valerosos manchegos. La religión, la patria y la violación de los más sagrados

23 J. A. Casquero Fernández y M. A. Jaramillo Guerreira, "Nuevas aportaciones documentales para la biografía de Juan Bautista Erro. El archivo del Marquesado de Grox", Sancho el Sabio: Revista de cultura e investigación vasca, $\mathrm{n}^{\circ} 5$ (1995), pp. 339-358.

24 J. A. García Noblejas, "Don Juan Bautista de Erro y Azpiroz, erudito, político y presidente de la Junta de Gobierno de La Mancha durante la Guerra de la Independencia”, Cuadernos de Estudios Manchegos, Ciudad Real, $\mathrm{n}^{\circ} 13$ (1982), pp. 59-68.

25 AHN, FC-Ministerio de Hacienda,1235,Exp.35.

26 Archivo Histórico Nacional. 
derechos de la sociedad claman por la venganza y por vuestra seguridad. Alarma juventud animosa antes que el arrepentimiento os haga conocer tarde la utilidad de este consejo".

Acabada la guerra, Fernando VII le designa el 14 de junio de 1814 Intendente de Madrid y su provincia y en 1818 Intendente del ejército y principado de Cataluña. Durante el trienio liberal 1820-1823, se retiró a Francia y trabajó por la abolición de la Constitución de 1812 y el restablecimiento del poder real. Como reconocimiento, Fernando VII le nombra en mayo de 1823 Ministro Secretario de Hacienda y Consejero de Estado.

Problemas en la corte madrileña de Fernando VII, le llevaron desterrado a ocupar cargos en Valladolid y Sevilla hasta que en 1833 con la muerte del monarca, pasó a Gibraltar y posteriormente a Inglaterra y Francia, desde donde se incorporó activamente al bando carlista. El Infante Don Carlos le nombró en 1836 Ministro Universal de Hacienda. En julio de 1837 resultó herido en la batalla de Chiva.

Exiliado en Montpellier (Francia), en 1850 estableció su residencia en Bayona donde falleció el 5 de enero de $1854^{27}$.

- Manuel González de Salcedo

Cura de Herencia.

- Juan Antonio de Santamaría

Presbítero vecino de Valdepeñas y abogado de los Reales Consejos. Elegido el 26 de junio de 1813 en la Iglesia Parroquial de Santa María del Prado de Ciudad Real para completar el cupo de diputados de las Cortes Generales y Extraordinarias por la provincia de La Mancha ${ }^{28}$.

No llegó a tomar posesión por padecer unas "calenturas catarrales con bastante destemplanza de cabeza”, según certificó en Valdepeñas el médico Diego Basco Arroyo el 18 de julio de 1813.

\section{Diputados por las provincias de la actual Castilla-la Mancha EN LAS CORTES GENERALES Y EXTRAORDINARIAS}

A la provincia de Cuenca, con 294.290 habitantes, se le asignaron seis diputados y dos suplentes. Estaban incluidos también en Cuenca los territorios de Casas Ibáñez y la Roda (hoy de Albacete) y la parte sur de Guadalajara (zona norte del partido de Huete-Sacedón y Señorío de Molina). La provincia de Guadalajara incluía también la zona madrileña de Buitrago y Colmenar Viejo. A sus 121.115 habitantes le correspondían dos

27 Diario Oficial de Avisos de Madrid, 10 de enero de 1854.

28 ACD, Serie documental electoral, $2, \mathrm{n}^{\circ} 8$. 
diputados y un suplente. A Toledo, con 374.867 habitantes distribuidos en un territorio con límites similares a los actuales más algunos de la provincia de Madrid, le tocaba elegir siete diputados y dos suplentes. Albacete se encontraba dividida administrativamente, entre La Mancha, Cuenca y Murcia. El señorío de Molina de Aragón empezó en esa época a perder su autonomía para pasar a integrarse en la provincia de Guadalajara. A pesar de no ser convocados para elegir diputados, nombró representantes y sus poderes fueron aprobados de forma excepcional el 1 de noviembre de 1810 por el patriotismo de sus habitantes en la lucha contra los franceses.

a) Los diputados por el Señorío de Molina en las Cortes Generales y Extraordinarias fueron:

- Francisco López Pelegrín, (1776-1817): Nació en Checa, abogado y propietario liberal, procurador general del Señorío de Molina, elegido el 11 de febrero de 1810. Defendió los tradicionales derechos del Señorío de Molina y de sus gentes.

- José Roa y Fabián: Elegido por el Señorío de Molina el día 19 de febrero de 1810, canónigo de la Santa Iglesia de Valencia. Fue uno de los firmantes de la Constitución.

b) Cuenca:

La elección de los diputados por la provincia de Cuenca se realizó en las salas consistoriales de la capital el 11 de febrero de 1810, extendiéndose los poderes el día 13.

Diputados elegidos que firmaron la constitución:

- Manuel de Rojas y Cortés: Natural de Jorquera, donde nació el 24 de diciembre de 1757, oficial de la secretaría de Hacienda.

- Alfonso Núñez de Haro, Nació en Villagarcía del Llano en 1762.

- Diego Ventura de Mena y Cortés (1772-1815): Conde Buenavista Cerro. Nacido en Belmonte. Militar de pensamiento absolutista, ya con la reacción absolutista de 1814 se erigió en delator de los más significados diputados liberales.

- Diego Parada Bustos (1763 Huete-1831 Madrid), abogado de los Reales Consejos y del Gremio y claustro de la Universidad de Alcalá de Diputados que no firmaron la constitución o no tomaron posesión:

- Felipe Mirallas: Nacido en Cañaveruelas, canónigo penitenciario de la Catedral de Valencia. Elegido el 11 de febrero de 1810, fue sustituido por José Lucas Ortega al fallecer el 22 de diciembre de 1810.

- Policarpo de Zorraquín: Diputado desde el 24 de abril de 1813 hasta la finalización de las sesiones el 24 de septiembre de 1813. 
- Fernando Casado de Torres: Nacido el 30 de mayo de 1757 en Zafra, Brigadier de artillería de marina. Elegido el 11 de febrero de 1810 no se presentó en las Cortes.

- Ramón Macía Lleopart: Nació en Cataluña en 1774, Corregidor de Cuenca y ex Consejero de Castilla, fue elegido el 15 de febrero de 1810 pero el Consejo de Regencia anuló su nombramiento por ser un "corregidor sin arraigo".

- Ramón Falcón de Salcedo: Nacido en Sigüenza el 26 de marzo de 1752, falleció en 1826. Fue obispo de Cuenca. Elegido el 3 de septiembre de 1810 en sustitución de Ramón María Lleopart, las Cortes anularon sus poderes.

- Antonio García Gómez: Elegido el 16 de febrero de 1810 no se presentó en las Cortes (desertó y se unió a los franceses) y fue sustituido por Mateo López.

- Mateo López: Diputado del Común del ayuntamiento de Cuenca, elegido diputado en sustitución de Antonio García Gómez, las cortes anularon sus poderes al no existir renuncia formal del anterior.

- José Ortega Lucas: Abogado de los Reales Consejos, elegido diputado suplente el 13 de febrero de 1810, no llegó a tomar posesión pese a ordenárselo las cortes para sustituir a Felipe Mirallas.

- Pedro Pinuaga: Oidor de la Audiencia de Valencia, elegido el 11 de febrero de 1810, no formó parte de las Cortes.

c) Toledo:

- Rafael Manglano y Quijano: Nació en Ocaña en 1754. Mariscal de Campo de los Reales Ejércitos. Elegido diputado suplente se incorporó a la cortes el 23 de septiembre de 1810, fue uno de los firmantes de la Constitución.

- Juan Jerónimo Chacón: Diputado del 22 de agosto al 20 de septiembre de 1813.

- Nicanor García Santos: Diputado del 22 de agosto al 20 de septiembre de 1813.

- Lorenzo Igual de Soria: Obispo de Plasencia, diputado del 22 de agosto al 20 de septiembre de 1813.

- Vicente de la Llave Valdés: Diputado del 22 de agosto al 20 de septiembre de 1813.

- Juan José Montero: Diputado del 22 de agosto al 20 de septiembre de 1813.

- Victoriano Sánchez: Diputado del 22 de agosto al 20 de septiembre de 1813. 
- Silvestre Trigueros: Diputado del 22 de agosto al 20 de septiembre de 1813.

- Gaspar Gómez de Alía: Nació en Horcajo de los Montes el 23 de febrero de 1740. Regidor de Toledo, fue elegido el 30 de noviembre de 1812 diputado propietario para las ciudades con voto en Cortes. Su avanzada edad y un accidente sufrido en Siruela cuando viajaba a Cádiz, le hicieron renunciar al cargo siendo sustituido por José Mariano del Pozo.

- José Mariano del Pozo: Procurador síndico del ayuntamiento de Toledo. Sustituyó a Gaspar Gómez de Alía, pero no llegó a formar parte de las Cortes al no presentarse antes de la clausura de las sesiones.

Fueron elegidos diputados suplentes y no llegaron a ocupar sus cargos:

- Simeón Palomino

- Justo Peñalver.

d) Guadalajara:

La elección de diputados se hizo el día 12 de marzo de 1810 por los diez electores en el ayuntamiento de Anguita, al estar la capital ocupada por los franceses.

- José María Veladíez y Herrera: Abogado doctor en derecho, vecino de Miedes de Atienza. Firmó la constitución pero causó baja como diputado el 20 de julio de 1812 al anular las Cortes su elección.

- Pedro Inocencio Bejarano: Obispo de Sigüenza, elegido el 6 de febrero de 1810 por la Junta de Defensa de Guadalajara, las cortes anularon su elección siendo nombrado posteriormente por Granada.

- Andrés Esteban Gómez: Canónigo de Sigüenza, vocal de la Junta de Guadalajara. Nació en noviembre de 1766 en Alustante (Guadalajara) y falleció en Jaén en 1831. Las Cortes anularon su elección tras haber ejercido como diputado 1 año y 9 meses.

- José Antonio González: Abogado de los Reales Consejos. Elegido el 27 de septiembre de 1812 no llegó a formar parte de las cortes.

- Manuel Morales Segoviano: Catedrático de la Universidad de Alcalá de Henares, elegido el 27 de septiembre de 1812 en el salón de sesiones de la Junta Superior de Guadalajara.

- Cristóbal Romero: Cura párroco de Torrebeleña, fue elegido en principio el 12 de marzo de 1810, pero no llegó a formar parte de las Cortes hasta una nueva elección el día 27 de septiembre de 1812, por cinco votos de los diez electores correspondientes en la sala de sesiones de la Junta Superior de Guadalajara.

- José María Torres y de la Bastida, Marqués de Villamejor: Regidor del ayuntamiento de Guadalajara. Nació en 1769 y falleció el 6 de julio de 1821. Elegido el 12 de marzo de 1810, sus poderes fueron anulados. 


\section{FUENTES DOCUMENTALES CONSULTADAS}

Archivo de la Diputación de Ciudad Real (ADCR).

Archivo del Congreso de los Diputados (ACD).

Archivo Diócesis de Ciudad Real (ADCR).

Archivo Histórico Nacional (AHN).

Archivo Histórico Provincial de Ciudad Real (AHPCR).

Biblioteca Nacional (BN).

Centro de Estudios de Castilla-La Mancha (CECLM).

BibliogRAFÍA CONSULTADA

ALMARCHA JIMÉNEZ, P., La guerra de la independencia en Membrilla, 1808-1814, Ciudad Real, Ayuntamiento de Membrilla y Diputación de Ciudad Real, 2008.

AMADOR FRESNEDA, J. Á., Historia de Villanueva de la Fuente. Religiosos Manchegos de los siglos XVI y XIX, Ciudad Real, Grupo de Desarrollo Rural Tierras de Libertad, 2011.

ARTOLA, M., Partidos y programas políticos 1808-1936, Madrid, Aguilar 1974.

CANDEL CRESPO, F., "Tres obispos albacetenses en la España de Fernando VII", Al-Basit, Albacete, no 35 (1994), pp. 113-132.

CASQUERO FERNÁNDEZ, J. A. y M. Á. JARAMILLO GUERREIRA, "Nuevas aportaciones documentales para la biografía de Juan Bautista Erro. El archivo del Marquesado de Grox", Sancho el Sabio: Revista de cultura e investigación vasca, $\mathrm{n}^{\circ} 5$ (1995), pp. 339-358.

GARCÍA NOBLEJAS, J. A., "Don Juan Bautista de Erro y Azpiroz, erudito, político y presidente de la Junta de Gobierno de La Mancha durante la Guerra de la Independencia”, Cuadernos de Estudios Manchegos, Ciudad Real, ${ }^{\circ} 13$ (1982), pp. 59-68.

GONZÁLEZ CALLEJA, E. y J. MORENO LUZÓN, Elecciones y parlamentarios, dos siglos de historia en Castilla-La Mancha, Toledo, JCCM 1993.

JIMÉNEZ BALLESTA, J., El Campo de Montiel, 1808-1814, Guerra de la Independencia, Madrid, Llanura, 2008.

JIMÉNEZ BALLESTA, J., Torre de Juan Abad en su historia. La huella de Quevedo, Madrid, Ayuntamiento de Torre de Juan Abad, 2011.

SÁNCHEZ CARCELÉN, A., "Eclesiásticos catalanes y las Cortes de Cádiz”, Anuario de Historia de la Iglesia, vol. 19 (2010), pp. 119-140. 